\title{
Harvard 'starts inquiry' into UFO researcher
}

Boston. Harvard University is said to have set up a special faculty committee to investigate research by John Mack, professor of psychiatry at the Harvard Medical School, into the experiences of those who claim to have been abducted in Unidentified Flying Objects (UFOs).

The university has declined either to confirm or deny the existence of the committee, or to give details of its powers or the terms of reference under which it is said to have been set up.

But it is understood that the committee has been formed by Daniel Tosteson, dean of the medical school, and is headed by Arnold Relman, former editor of the New England Journal of Medicine and currently a professor emeritus at the medical school.

Those who say they are familiar with the investigation maintain that Mack's work with patients claiming to have been abducted by extraterrestrial beings has become a source of embarrassment to the university.

Extracts from what is purported to be a draft report of the committee criticize Mack for failing to require physical evidence from those claiming to have been abducted, and say it was "professionally irresponsible" for him to lend credence to reports of extraterrestrial contact. But supporters claim that his academic freedom is being threatened.

Mack is a former chair of the school's department of psychiatry. His bestselling book, Abduction: Human Encounters With

\section{Canada to get own science satellite}

Washington. Thanks partly to Canada's participation in the international space station, Canadian scientists will soon get their first chance in 30 years to lead the design of a scientific satellite, SciSat 1.

This is the first of two satellites that will be financed by the Canadian Space Agency (CSA) and launched by the US National Aeronautics and Space Agency in 1999 and 2004 respectively. Both will be launched without charge on a Pegasus launcher - a rocket mounted underneath an aircraft - as part of a deal to ensure continued Canadian participation in the space station.

Within the next two months, the CSA will invite proposals to design the first SciSat satellite. Gerry Atkinson, chief scientist at the agency's space sciences programme, expects about a dozen groups to apply. The winner will be chosen by early 1997 .

Some scientists have suggested that the C $\$ 35$ million (US\$25 million) being made available to design and build each of the SciSats is insufficient, especially as CSA rules stipulate that instruments cannot be assembled cheaply in universities, but must be built by Canadian industry.

But Atkinson says that the sum, approved
Aliens, has been promoted on television and radio talk shows throughout the country.

His critics say he has abandoned scientific objectivity and may have elicited memories of abductions through hypnosis. "Mack is an exceedingly naive man who can't believe that people lie or make up stories," says James Randi, an internationally renowned sceptic of paranormal phenomena.

Mack himself declines to discuss the activities of the committee, whose existence was reported last month in both the Boston Globe and the university student newspaper, the Harvard Crimson.

But academic UFO investigators, such as David Pritchard, a physicist at the Massachusetts Institute of Technology, believe that Harvard is infringing Mack's freedom of inquiry. "He is subject to an investigation that, as far as I can tell, has not been initiated by the faculty," says Pritchard. Other Mack sympathizers go further, calling the proceedings against him a "witch-hunt".

Beverly Rubik, director of the Center for Frontier Studies at Temple University, says that "putting the lid on Mack would be bad policy for Harvard and bad for science in general." She adds: "Science moves forward when people start asking new questions."

John Miller, a physician with the Southern California Permanente Medical Group, who has interviewed more than 200 individuals reporting abduction experiences, claims in a letter to the faculty committee that the

by the Canadian government, is what the space agency had argued was needed. Canada also hopes to attract overseas partners to build one or two extra instruments - estimated to cost between $C \$ 5$ and $C \$ 10$ million each - for the first SciSat.

Fierce competition to design the first satellite is expected from three disciplines astronomers, Earth scientists who want to study the atmosphere, and scientists interested in the interaction between solar rays and the upper atmosphere. At least one group of astronomers, led by Slavek Rucins$\mathrm{ki}$ at the University of Toronto, is already planning a bid to use the satellite for ultraviolet astronomy.

Canada has not led a project to design and build its own scientific satellite since the 1960 s, preferring to collaborate with countries such as Sweden. Atkinson concedes that this has led to "some frustration" among Canadian scientists.

The space agency considered soliciting bids for both SciSats simultaneously. But, because of the length of time before the planned launch of SciSat 2, it has decided to select only a design for the first satellite at this stage.

Colin Macilwain controversy "has more to do with academic freedom than [with] aliens or UFOs".

The letter was sent in response to a request by Daniel Sheehan, Mack's former lawyer based in California, who has sent similar requests to several other UFO or abduction 'experts' asking them to write statements in Mack's defence. Excerpts supposedly taken from a draft report of the committee, and quoted by Sheehan, have been transmitted over the Internet.

Roderick MacLeish, Mack's attorney, says that "Sheehan does not represent Mack, nor was he authorized to send that material over the Internet." But Pritchard claims that the tactic was successful in "raising a furore" over the Harvard inquiry and bringing the matter to public attention.

In his letter, Miller cites several weaknesses in what Sheehan claims to be the preliminary findings of the committee report. He takes issue, for example, with the com-

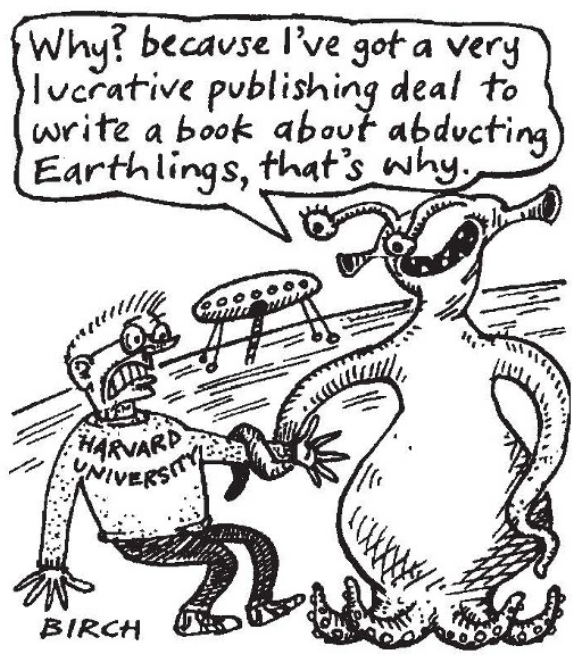

mittee's insistence that Mack should have corroborated patients' stories with physical evidence of their supposed abduction. "A psychiatrist is supposed to deal with patients in a therapeutic setting, not go out in the field and gather forensic evidence," he says.

Miller also says that "at times, it may be more responsible to let patients hold onto their beliefs - even if they are based on a delusion - than to shatter those beliefs entirely". He also criticizes the fact that no members of the committee appear to have met anyone claiming to have been abducted. "I was taught at medical school that you can learn a lot from people just by listening to them carefully," says Miller.

"Although the origins of the syndrome are unknown, and uncertainties abound, one thing can be said for sure: these people, who consider themselves 'abductees,' do exist," he says. "They can be studied, and something can be learned from this process, even if the whole phenomenon turns out to be a product of the human mind." Steve Nadis 